\section{Cloning cookbook for the laboratory}

\section{Kevin Struhl}

A Practical Guide to Molecular Cloning. By Bernard Perbal. Wiley: 1984. Pp.554. Hbk £68.85, \$59.50; pbk £39.90, \$34.50.

TEN years ago, molecular cloning was an art that was practised only in a few Californian laboratories. Now, with everyone and his brother involved in recombinant DNA manipulations, the field has exploded into a vast and complex technology that is far beyond the ability of an individual to learn and remember completely. Furthermore, because these techniques have become invaluable in almost all fields of biological science, it is frequently the case that those who want to use them are not trained as molecular biologists. In short, there is a great need for a cookbook, which contains a reasonably complete collection of recipes that are easy to follow and up to date.

Three years ago Cold Spring Harbor Laboratory published such a collection, Molecular Cloning: A Laboratory Manual by Maniatis, Fritsch and Sambrook. This book is omnipresent in molecular biology laboratories and is utilized to the point where it is frequently referred to as "The Bible". Although experts usually use shortened versions of the procedures, the methods are clearly described and they do work. Indeed, the only shortcoming of this manual is its age. It does not contain anything on the production of monoclonal antibodies and related methodologies, now standard tools of the trade, and the section on expression vectors for the controlled production of gene products is weak and out-dated. An updated version is clearly necessary, and the authors are, in fact, preparing a new edition.

What does A Practical Guide to Molecular Cloning offer that the earlier book lacks? Unfortunately, the answer is not much. The most practical addition is that of DNA sequencing using single-stranded DNA vectors and primer extension with di-deoxy nucleotide precursors. However, most commercial suppliers enclose an equally detailed protocol on purchase of the reagents. The author also describes a number of techniques for the purifica-

\section{New in paperback}

- Quarks, Gluons and Lattics by M. Creutz. Publisher is Cambridge University Press, price is $£ 7.95, \$ 12.95$. For review see Nature 309, 290 (1984).

- From Folk Psychology to Cognitive Science: The Case Against Belief by Stephen Stich. Publisher is MIT Press, price is $\$ 8.95, £ 8.95$. For review see Nature 309, 815 (1984).

- Ontology and Phylogeny by Stephen Jay Gould. Publisher is the Belknap Press of Harvard University Press and the price is $\$ 8.95$, $£ 8.25$. tion of large quantities of DNA. These methods are seldom used and the descriptions read suspiciously like the promotional literature from the companies that sell the products.

Given the need to include newer techniques, Perbal devotes an inordinate number of pages to unnecessary matters. More than 20 per cent of the book is spent on lists of restriction endonucleases and vectors; such information, although useful, is easily found in the catalogues of commercial enzyme suppliers. Thirtythree pages are devoted to a "theoretical study of the fraction of a long-chain DNA that can be incorporated in a recombinant DNA partial-digest library" and the representation of DNA sequences in such libraries. I don't know anyone who uses this information on a practical basis; moreover, the few qualitative aspects worth knowing are buried among pages of mathematical formulae.

Members of my laboratory found Per-

\section{Genesis of man}

\section{Harry V. Merrick}

African Archaeology. By David W. Phillipson. Cambridge University Press: 1985. Pp.234. Hbk£25, \$39.50; pbk£9.50, $\$ 14.95$.

OVER the past two decades the pace of prehistoric archaeological research in Africa has accelerated enormously. Although recent work frequently has not produced as visually spectacular discoveries as in other parts of the world, it has been of the first order of importance in elucidating earlier human behaviour, especially during the Stone Age. Far from being a culturally stagnant cul-de-sac during the course of human evolution, Africa has often displayed a technological precociousness that would have astounded prehistorians 20 years ago.

In this book Dr Phillipson has brought together the new findings with earlier research to produce a very readable, relatively non-technical survey of the current state of knowledge of African prehistory. It is both timely and urgently needed; the last comparable synthesis is now 15 years old and has been largely superseded by recent events.

African Archaeology is very much a traditional, narrative account of the main stages of human development in Africa, emphasizing subsistence patterns and general ways of life. Each stage is presented in a series of regional summaries, accompanied by illustrations of the principal sites and representative tool and pottery types. Fortunately, much of the nomenclature and the intricacies of stone tool classification, which have dominated chronological and cultural reconstructions in African prehistory, are bal's book much harder to use than its competitor. One problem is that the book is bound in a conventional fashion, as compared to the earlier manual which comes as a spiral notebook. This seemingly trivial difference is actually of practical importance because Maniatis $e t$ al. lies flat and is thus easy to read on a laboratory bench, its natural habitat. Another problem is that the experimental protocols appear in large print, whereas explanatory paragraphs appear in small print. This is visually uncomfortable, and the large print for the protocols coupled with the small page size means that many techniques are spread out over a number of pages.

Thus it seems to me that the Maniatis et al. manual is still the best around, and the revised version should be even better.

Kevin Struhl is in the Department of Biological Chemistry, Harvard Medical School, Boston, MA 02115, USA.

neatly bypassed using Grahame Clark's scheme of technological modes to describe levels of technological complexity without temporal connotations. Nonetheless, details of chronology and technology still loom large for the first two million years of prehistory recounted in the first third of the volume. However, for the past several millennia, and especially for the Subsaharan region, Phillipson combines the findings of archaeology, including results from his own considerable field work, with linguistic and historical evidence and oral tradition to produce a much fuller view of emerging African societies in each part of the continent. This is an approach which also encourages appreciation of some of the environmental, economic and social factors underlying the cultural diversity of modern African peoples.

The bold attempt to encompass over two million years of a continent's prehistory in a single volume has understandably necessitated a synoptic treatment of most of the more controversial issues in African prehistory. While the superficial treatment of these problems may be trivial in the broader context of a continent-wide survey, regrettably it represents a missed opportunity to convey the excitement in African archaeological research today and the increasing inclination towards problem-orientated research. That apart, the book is impressively comprehensive, well-referenced and concise. It will be of particular interest to a broad range of Africanists and archaeologists, and of value as an introductory textbook for courses which cover African prehistory and history.

Harry V. Merrick is Head of the Division of Archaeology at the National Museums of Kenya, PO Box 40658, Nairobi, Kenya. 